\title{
Políticas Públicas E SEUS CiClos Na ÁREa EdUCACIONAL: O CASO do ENSINO DE MÚSICA
}

\author{
Public Policies ANd Their CyCles in the Educational AREA: The \\ CASE OF MUSIC TEACHING
}

\author{
Breno Henrique Matias \\ Universidade Federal de Ouro Preto - UFOP \\ Mestrando em Educação - UFOP \\ Ouro Preto, MG - Brasil \\ brenohenriquematias@gmail.com
}

\author{
(D) José Rubens Lima Jardilino \\ Universidade Federal de Ouro Preto - UFOP \\ Doutor em Ciências Sociais pela Pontifícia Universidade Católica de São Paulo \\ Professor do Doutorado e Mestrado em Educação da UFOP \\ Ouro Preto, MG - Brasil \\ jrjardilino@gmail.com
}

Resumo: Este artigo faz uma análise da Lei no 11.769/2008, que instituiu a música na escola como conteúdo da educação básica. Partindo da concepção de políticas públicas, tomará como aporte teórico os ciclos de políticas considerando a demanda inicial até a sua implementação. Metodologicamente este artigo se ampara na análise documental buscando demonstrar a importância da atuação/intervenção direta dos burocratas e de sua discrição no resultado esperado ao inserir a música na escola. Concluímos que a inserção ou não da música na escola foi tratada com dubiedade. Nos processos de implementação a discrição, imperou mais que a própria lei, levando a música a não se tornar uma disciplina escolar na educação brasileira.

Palavras-chaves: Políticas Públicas. Educação Musical. Educação Básica.

Abstract: This article analyzes Law 11.769 / 2008, which instituted music at school as the content of basic education. Starting from the conception of public policies, it will take as theoretical contribution the policy cycles considering the initial demand until its implementation. Methodologically this article is based on documentary analysis seeking to demonstrate the importance of the bureaucrats' direct action / intervention and their discretion in the expected result when inserting music in school. We conclude that the insertion or not of music in school was treated with doubt. The implementation processes discretion prevailed more than the law itself, leading music not to become a school discipline in Brazilian education.

Keywords: Public Policies. Musical education. Basic education.

\section{Introdução}

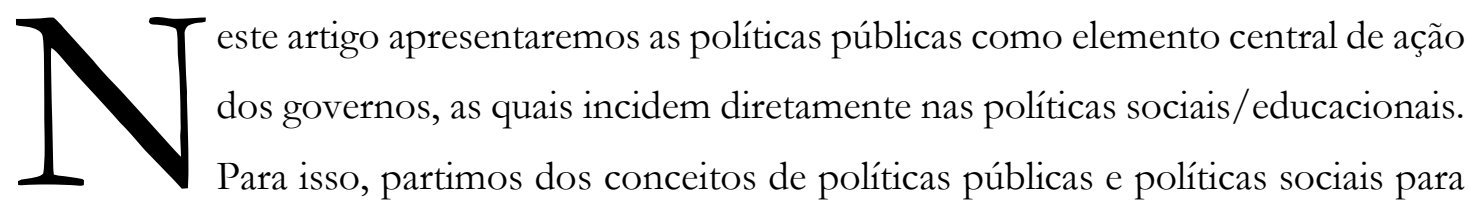


compreender como elas surgem, como são implementadas, quem interfere diretamente ou indiretamente para que elas funcionem e quais são seus ciclos.

Utilizaremos para análise os conceitos de políticas públicas apresentados por Souza (2006) e Rua (1998), de políticas sociais por Carvalho (2007) e do ciclo de políticas públicas e suas abordagens por Mainardes (2006). Apresentaremos também discussão sobre a ação dos burocratas e sua conceituação, trazidas por Meyers e Vorsanger (2013), além um corpus legislativo. Toda essa primeira parte do artigo, que apresenta diversos conceitos no campo da política, servirá de aporte teórico para a análise da Lei no 11.769/2008, considerando que esta foi uma política educacional que pretendia colocar a música como conteúdo obrigatório na educação básica. Analisaremos o seu surgimento, os contextos que a influenciaram, os atores envolvidos, a sua implementação, as modificações e os resultados alcançados a luz dos conceitos e autores abordados neste texto.

\section{Discussão conceitual}

As políticas públicas fazem parte do nosso cotidiano e, muitas vezes, nós não nos damos conta do quanto elas estão presentes, da sua função na sociedade, de como somos geridos por várias delas e de como acabamos influenciando não só seu surgimento, mas também suas modificações. Ao falarmos de política pública, é preciso discutir seu conceito para podermos avançar um pouco mais e analisar sua função. Para isso, iniciaremos com o conceito de políticas públicas apresentado por Souza (2006, p. 26) que discute a política pública como o "campo do conhecimento que busca, ao mesmo tempo, "colocar o governo em ação" e/ou analisar essa ação (variável independente) e, quando necessário, propor mudanças no rumo ou curso dessas ações (variável dependente)".

Dessa forma, utilizando-se das políticas públicas, os governos entram em ação, definindo e formulando as políticas que representam o Estado que se quer propor. Entretanto, não é uma tarefa fácil, levando-se em conta as pressões de grupos de interesse e dos movimentos sociais, tornando a formulação um campo de conflitos.

Outra autora que nos auxiliará nessa discussão sobre as políticas públicas é Rua (1998, p.12) ao afirmar que:

As políticas públicas (policies), por sua vez, são outputs, resultantes das atividades política (politics): compreendem o conjunto das decisões e ações relativas à alocação imperativa de valores. Nesse sentido é necessário distinguir entre política pública e decisão política. Uma política pública geralmente envolve mais do que uma decisão e requer diversas ações estrategicamente selecionadas para implementar as decisões tomadas. Já uma decisão política corresponde a uma escolha dentre um leque de alternativas, conforme a hierarquia das preferências dos atores envolvidos, expressando - em maior ou menor grau - uma certa adequação entre os fins pretendidos e os meios disponíveis. Assim, embora uma política pública implique decisão política, nem toda decisão política chega a constituir uma política pública. Um exemplo encontra-se na emenda constitucional para 
reeleição presidencial. Trata-se de uma decisão, mas não de uma política pública. Já a privatização de estatais ou a reforma agrária são políticas públicas.

Rua (1998), a exemplo de Souza (2006), também aponta as políticas públicas são aquelas que se exercem por meio de ações do governo. Entretanto, Rua faz um desdobramento ao demonstrar que a política pública advém de uma decisão no âmbito político e ainda chama a atenção para um fator importante, ao mencionar que nem toda decisão política se reverte em política pública.

É necessário compreendermos e analisarmos como essas políticas surgem e também como são classificadas as suas fases, levando-se em conta que as políticas públicas não são escolhidas por acaso, nem seu percurso é aleatório.

Um dos caminhos a ser percorrido pode ser chamado de ciclo da política pública, ressaltando que o termo "pública" é uma prerrogativa do Estado, visto sua finalidade na coisa pública. Para Souza (2006, p. 29)

O ciclo da política pública: Esta tipologia vê a política pública como um ciclo deliberativo, formado por vários estágios e constituindo um processo dinâmico e de aprendizado. $\mathrm{O}$ ciclo da política pública é constituído dos seguintes estágios: definição de agenda, identificação de alternativas, avaliação das opções, seleção das opções, implementação e avaliação.

Souza (2006) traz um caminho a ser percorrido via ciclo de política, que é apenas uma forma de análise, pois há outras concepções, como veremos adiante. Torna-se importante salientar que Souza traz uma divisão dessas etapas dentro de um determinado ciclo, demonstrando que as políticas podem e devem ser analisadas por este viés.

Mainardes (2006) faz distinções importantes dessas etapas e as classifica também em ciclos, assim como Souza, apresentando as concepções conceituais desses ciclos de políticas, apoiando-se em estudos de Stephen Ball e Richard Bowe, ingleses que pesquisaram o campo das políticas educacionais. Mainardes (2006) menciona que o ciclo de política se baseia no contexto da influência, no contexto da produção de textos e no contexto da prática.

No contexto da influência é onde geralmente as políticas públicas se iniciam e se constroem como discursos políticos e ligados aos interesses de ideologias dogmáticas. Já no contexto da produção de textos, há a elaboração dos textos da política representados por textos oficiais, textos políticos, comentários formais ou informais sobre os textos, pronunciamentos oficiais etc. Esses textos são resultados de disputas e acordos. O último é o contexto da prática, no qual a política 


\title{
e-ISSN: 2525-3514
}

está sujeita a recriações e interpretações, produzindo efeito, consequência e até mudança na política original, por haver pluralidade de leituras e de leitores

Rua (1998) faz referência a outros termos para classificar o surgimento da política pública, apresentando a expressão Inputs como sendo demandas de entrada de políticas, aquela que surge do meio ou dos contextos sociais, aquilo que faz surgir a necessidade de intervenção através de uma política. Outra expressão é Withinputs, também sendo como demanda de política pública, mas surgida diretamente no interior meio político.

É interessante que Rua aponta, dentro dessa perspectiva das políticas públicas, que há situações que são consideradas "Estado das Coisas", ou seja, quando há um problema determinado que não chega a incomodar de forma enfática, mas que este estado, ao se transformar em um problema político, requerendo ação política, passa a figurar como item prioritário e entra para a agenda governamental. Mas que para isso aconteça é necessário que:

(a) mobilize ação política: seja ação coletiva de grandes grupos, seja ação coletiva de pequenos grupos dotados de fortes recursos de poder, seja ação de atores individuais estrategicamente situados;

(b) constitua uma situação de crise, calamidade ou catástrofe, de maneira que o ônus de não resolver o problema seja maior que o ônus de resolvê-lo;

(c) constitua uma situação de oportunidade, ou seja, haja vantagens, antevistas por algum ator relevante, a serem obtidas com o tratamento daquele problema. (RUA, 1998, p.6)

Nesse momento, Rua (1998) discute como um problema entra para a agenda e a partir daí requer ação governamental. Ele pode ser transformado em política pública, dependendo da natureza da situação, tornando-se demanda de Input, o que exige formulação de alternativas para resolução. E traz à tona os conflitos de interesses, de influências, de preferências e de poder dos atores envolvidos, gerando alianças, disputas, lutas jogos e debates, havendo troca de favores em prol de apoio.

Ao pensarmos na agenda recorremos a Souza (2006, p. 30) que traz três abordagens sobre como se definem as agendas:

\begin{abstract}
A primeira focaliza os problemas, isto é, problemas entram na agenda quando assumimos que devemos fazer algo sobre eles. O reconhecimento e a definição dos problemas afetam os resultados da agenda. A segunda resposta focaliza a política propriamente dita, ou seja, como se constrói a consciência coletiva sobre a necessidade de se enfrentar um dado problema. [...] A terceira resposta focaliza os participantes, que são classificados como visíveis, ou seja, políticos, mídia, partidos, grupos de pressão, etc. e invisíveis, tais como acadêmicos e burocracia. Segundo esta perspectiva, os participantes visíveis definem a agenda e os invisíveis, as alternativas.
\end{abstract}

A entrada na agenda de um determinado elemento precisa se tornar um "problema" com necessidade de intervenção de uma política pública a fim de enfrentá-la com normas e leis que serão aplicadas por um determinado participante. Nesse contexto temos a influência de grupos que 
-ISSN: 2525-3514

pressionam tanto para o problema entrar na agenda quanto na forma com que ele deve ser resolvido, além da produção de textos regulatórios que serão colocados em funcionamento.

Para Rua (1998), quando o problema entra para a agenda governamental, tornando-se demanda de Input, tende-se a pensar soluções em três âmbitos. O primeiro refere-se ao Modelo Incremental, em que a solução pode não introduzir grandes mudanças na situação existente, buscando, na verdade, o melhor acordo dos interesses entre os envolvidos. O segundo é o Modelo Racional-Compreensivo, que busca conhecer o problema a fim de tomar decisões de grande impacto, maximizando valores e alternativas. E, por isso, é uma decisão mais lenta para que se possa analisar profundamente o assunto, os estudos e as viabilidades técnicas. Já o terceiro âmbito, apontado por Rua (1998), é o Mixed-scanning, que faz uma fusão entre o modelo incremental e o racional-compreensivo, em que a tomada de decisão pode se apoiar em uma revisão do campo de decisão, mas sem se dedicar a análise detalhada de cada alternativa, fazendo com que alternativas de longo prazo sejam analisadas e geradas decisões estruturantes.

Rua (1998) expressa que pode também haver o emperramento da resolução, quando o problema se torna parte da agenda. No entanto, traz tantos conflitos de interesses e sofre tantas influências que a sua decisão é adiada e colocada em modo de espera, não havendo decisão.

Souza (2006), por sua vez, apresenta que o caminho para se compreender as políticas perpassa a definição de agenda, a identificação de alternativas, a avaliação e a seleção das opções, a implementação e a avaliação, chamando a atenção que para que a agenda seja definida há ainda a abordagem da focalização do problema. A focalização busca a identificação tanto do problema quanto dos participantes, que são os grupos que podem forçar a entrada deste problema na agenda.

Mainardes (2006) afirma que o caminho de compreensão das políticas passa pelos contextos da influência, da produção de textos e o da prática, os quais geram as políticas públicas, desenvolvem as formulações de leis, decretos etc., sendo passíveis de análises.

Como trataremos do campo educacional, é importante discutirmos aqui também as políticas sociais que podem ser vistas de acordo Carvalho (2007, p. 75) como um "conjunto de diretrizes, orientações, critérios e ações que permitam a preservação e a elevação do bem-estar social, devendo proporcionar que os benefícios do desenvolvimento alcancem a todas as classes sociais com a maior equidade possível".

A Constituição Federal Brasileira de 1988 traz com clareza os direitos sociais em seu Capítulo II, artigo Art. 60, ao apresentar que: "são direitos sociais a educação, a saúde, a alimentação, o trabalho, a moradia, o transporte, o lazer, a segurança, a previdência social, a proteção à maternidade e à infância, a assistência aos desamparados". Podemos dizer que o Estado tem quer ser o responsável por promover ações que garantam os direitos sociais, visto que a maior 
lei brasileira traz esses direitos como garantia e como obrigação do próprio Estado, apontando em quais direções essas políticas precisam caminhar.

As políticas públicas funcionam como elementos estruturantes das ações que promovem as políticas sociais, mas não, necessariamente, são exclusivas para a agenda social, pelo fato de que nem toda política pública é política social ou se destina para tal. Contudo, é através da política pública que serão providas as políticas sociais.

É fato que as políticas sociais no Brasil ainda não são satisfatórias em sua relação de oferta e qualidade. Carvalho (2004) apresenta que o Estado brasileiro ainda possui dificuldades em sua atuação para que se tenha justiça social. No campo judicial, por exemplo, há ainda incapacidade de atender todos com a defensoria pública, pois existe muita demora nos processos. O Estado brasileiro ainda não conseguiu diminuir a desigualdade e nem os privilégios de determinados grupos, denominados elite e de primeira classe por Carvalho (2004). A outra, a segunda classe, é a dos cidadãos mais simples e sujeitos a leis e benefícios, trabalhadores assalariados e com carteira assinada, como vimos surgir na revolução industrial. Temos ainda a chamada terceira classe que vive sem trabalho assalariado, possui baixa escolaridade e tem seus direitos civis desrespeitados pelo governo, pela polícia e por outros cidadãos, valendo para eles apenas o Código Penal.

O Estado brasileiro ainda está longe do ideal preconizado pela constituição. Observamos que as ações não alcançam seus objetivos, como é o esperado pela população. Basta vermos como a educação ainda é precária, alcançando índices baixíssimos nos rankings e longe das metas estabelecidas, além dos problemas como saúde, desemprego, fome e segurança. Desta forma, o Estado tem de proporcionar políticas públicas para atender aos cidadãos.

Ao pensarmos em proposta de Estado, concepções de governo e implementação de políticas públicas e sociais, podemos destacar um participante que possui extrema importância ao colocar a regulamentação em prática, ao materializar os textos produzidos no campo político, ao representar fisicamente as ações do Estado, este é o burocrata.

\footnotetext{
Os burocratas, por sua vez, devem a sua posição à ocupação de cargos que requerem conhecimento especializado e que se situam em um sistema de carreira pública. Controlam, principalmente, recursos de autoridade e informação. Embora não possuam mandato, os burocratas geralmente possuem clientelas setoriais. Além disso, eles têm projetos políticos, que podem ser pessoais ou organizacionais (como a fidelidade à instituição, o crescimento da organização à qual pertencem, etc). Por isso, é comum haver disputas não apenas entre políticos e burocratas, mas também conflitos entre burocracias de diferentes setores do governo. (RUA, 1998, p.4)
}

Os burocratas podem ser vistos como a representação física e humana do Estado, trazendo consigo a possibilidade de colocar ou não em prática as definições regimentais das leis, utilizandose da discrição, que pode ou não colaborar com o indivíduo que sofre a ação do Estado e necessita de seus serviços. Não se trata de algo simples, os burocratas podem fazer funcionar uma política, 
podem, dentro de sua discrição, privilegiar algumas ações em detrimento de outras e, assim, serem responsáveis diretos pelo bom funcionamento ou não da implementação da política definida pelos formuladores.

Para Meyers e Vorsanger (2013), os burocratas têm a oportunidade significativa de influenciar a execução das políticas públicas pelo nível de interação direta com o cidadão, podendo haver variabilidade e imprevisibilidade ao empregar julgamento discricionário, superando a autoridade formal, operando como executores, mas também moldando os resultados das políticas ao interpretar regras, alocar recursos e tomando decisões produzindo a política como o cidadão a experimenta.

Um elemento importante a se destacar é o da discrição desse burocrata, ou seja, a forma como ele colocará em prática e interpretará os textos produzidos pelos formuladores. Isso pode fazer funcionar ou não uma determinada política pública, pois os burocratas são os que implementam a política e, desta forma, têm suas ações constantemente restringidas, na busca de controle para que a implementação siga os preceitos dos formuladores.

Não é tão simples ter o controle político sobre as ações dos burocratas, principalmente nos fatores que não são fáceis de serem mensurados e que dependem de interpretação do próprio burocrata em uma determinada ação. O campo político busca restringir a atuação por meio de regras e procedimentos que circundam a ação do implementador, entretanto, não é possível limitar o trabalho desse burocrata.

Os burocratas são responsáveis diretamente pela implementação das políticas públicas. Rua (1998) apresenta a implementação como ação, elemento que faz funcionar ou não uma política. Para este autor:

\footnotetext{
A implementação pode ser compreendida como o conjunto de ações realizadas por grupos ou indivíduos de natureza pública ou privada, as quais são direcionadas para a consecução de objetivos estabelecidos mediante decisões anteriores quanto a políticas. Em outras palavras, trata-se das ações para fazer uma política sair do papel e funcionar efetivamente. (RUA, 1998, p.14)
}

É nesse aspecto que podemos ver a centralidade e importância do burocrata, pois é aquele que interpreta o texto político e o transforma em ação, retirando-o do contexto da produção textual e levando-o para o contexto da prática, aplicando sua discrição. Se o formulador da política pública não levar em conta a atuação desse ator como elo entre teoria e prática, a política pública proposta pode não ser a aplicada no real, ou seja, no dia a dia. Seguindo por esta direção, Meyers e Vorsanger (2013) apresentam os burocratas como os servidores públicos que interagem diretamente com o 
cidadão, sendo eles trabalhadores de escolas, policiais, assistentes sociais, servidores que controlam o acesso a programas e/ou fazem cumprir as leis.

Rua (1998) menciona que uma política pode não ser implementada, por interesses contrários, reação de agentes públicos, omissão dos beneficiários, ou ainda ter apenas uma de suas partes implementada, gerando resultados diferentes daqueles esperados na decisão política. Portanto a implementação deve ser vista sob uma perspectiva interativa, na qual as ações individuais em pontos estratégicos influenciam consideravelmente os resultados obtidos.

\section{Analisando o surgimento e implementação da Lei no 11.769/2008}

A legislação brasileira no campo da educação está pautada através da Lei de Diretrizes e Bases da Educação Nacional (LDB) no 9.394/96. As políticas educacionais certamente gerarão alterações na LDB que serão promovidas pelas políticas públicas na busca de garantir educação como direito social. Entretanto, uma política nem sempre alcança seu propósito devido as ações de vários atores ou até mesmo indefinições e formulações mal elaboradas, gerando, assim, problemas na implementação.

Ao realizarmos análise da Lei Federal no 11.769/2008, que alterou o Art. 26 da LDB 9.394/96, em seu parágrafo $6^{\circ}$, colocando a música como conteúdo obrigatório, mas não exclusivo do componente curricular Artes, buscamos compreender os caminhos ou os ciclos de políticas, como nos trouxeram Souza (2006) e Mainardes (2006). Apresentaremos a análise através do referencial teórico já exposto, com o propósito de encontrarmos os contextos e as causas que fizeram com que esta lei não funcionasse efetivamente. Discutiremos as hipóteses na busca de compreendermos esta situação, analisando desde seu surgimento no "estado das coisas", a entrada na agenda governamental, a formulação, a construção dos textos legislativos e o contexto da prática via implementação, contemplando até a ação dos burocratas nesse processo.

A origem do movimento para levar a educação musical para as escolas não se inicia de fato no campo educacional. De acordo com Pereira (2010), em 2004 os músicos estavam se organizando em prol dos movimentos do Ministério da Cultura, que criaria as Câmaras Setoriais, específicas das áreas que compõem as artes e cultura no Brasil. Foram criados Grupos de Trabalho para discussão das necessidades da área musical com realização de encontros nacionais, juntamente com Associações representativas da música e dos músicos, bem como das representações do setor voltado para a educação musical.

Pereira (2010) menciona que foram elaborados documentos com propostas, voltadas para a criação do Plano Nacional de Cultura, entretanto, houve muita discordância e outros grupos 
e-ISSN: $2525-3514$

surgiram. Dentre eles destaca-se o Núcleo Independente de Músicos que se articulou com deputados federais com o objetivo de criar uma Frente Parlamentar Pró-Música no Congresso Nacional. Algumas ações foram realizadas por este grupo como a distribuição de um manifesto com as reivindicações, comunicados, boletins, audiências públicas e seminário, em que um dos painéis de debates foi o da Educação Musical e Difusão, contando com a presença da Associação Brasileira de Educação Musical - ABEM, que fortaleceu e ajudou a consolidar o pedido de inclusão da música no contexto escolar. Transformaram algo que estava no "estado das coisas" em um problema, movimentando a categoria e a sociedade civil, trazendo a educação musical como demanda Input. Estes aspectos também podem ser classificados como contexto da influência, conforme apresentado por Mainardes (2006).

Desta forma, os estudos de políticas públicas, assim como as fases de seu ciclo, se apresentaram de forma concreta e coerente no surgimento da demanda de música na escola e contribuíram para explicar o movimento inicial, formando o contexto da influência, o "estado das coisas" e levando ao primeiro aspecto apontado por Souza (2006), que é a definição da agenda.

Nesse momento, entra em ação o âmbito político, quando em 2008 foi apresentado no Senado o projeto de lei $\underline{n^{\circ}} 2732 / 2008$ que versava sobre a inclusão da música no ensino básico. O Senado e a Câmara Federal aprovaram o projeto que foi sancionado pelo Presidente da República e constituiu-se na Lei $n^{\circ} 11.769$, de 18 de agosto de 2008. A Música se tornava um conteúdo obrigatório a ser implantado em todas as escolas do país, a partir de agosto de 2011. Esse prazo de três anos era para a adequação das unidades de ensino.

Contudo, o artigo que determinava qual o profissional que atuaria no ensino desta disciplina foi vetado, uma vez que trazia como profissional o especialista, ou seja, profissional com formação específica, o licenciado em música. Como justificativa para o veto, o governo mencionou que a cultura popular musical pode ser ensinada por pessoas que detenham algum conhecimento musical, não necessariamente o especialista da área. Outro fator importante para o veto se deve ao fato da inexistência quantitativa de profissionais específicos para preencherem todas as vagas que seriam disponibilizadas.

O próprio veto ao profissional específico foi um elemento de enfraquecimento dessa política, tornado a música tão irrelevante que poderia ser ensinada por qualquer pessoa sem formação, mesmo sendo em um ambiente institucionalizado como as escolas. Isso não desqualificava apenas a música, mas também o profissional da educação.

O lugar que a música ocuparia também é um fator flutuante que foi imposto pelo conteúdo da lei. A música é apresentada como conteúdo, o que antes era linguagem que competia ao componente curricular Arte, não se tornando disciplina e ainda coexistindo com Arte. Em vista 
disso, não se tem uma definição de qual o era o espaço que ela deveria ocupar para fazer parte da educação.

É importante ressaltar a definição da música como conteúdo e não como disciplina, pois esse fator foi um argumento muito utilizado para que ela não fosse implementada no currículo escolar. Entretanto, segundo Queiroz (2013, p. 34) “não há na LDB nenhuma determinação para que a música seja considerada uma disciplina, como também não existe qualquer especificação de que áreas como biologia, ciências, geografia, história, língua estrangeira, entre outras, deverão ser disciplinas".

Era preciso pensar também no formato em que a música seria inserida no contexto da escola, pois havia uma repercussão da volta da música para a escola, como se ela já tivesse sido vista ou reconhecida como uma área do conhecimento. Segundo Sobreira (2008) volta é retorno de algo já ocorrido, o que poderia significar o Canto Orfeônico, mas que não era esse o desejo dos educadores.

Deveria ser estabelecido o mínimo de estruturação via legislação para sua organização, contudo, isso ficou sem definição, demonstrando, desde o início, que essas indefinições durante a decisão política e produção dos textos poderiam deixar a música a margem da educação básica, não lhe assegurando acesso e tampouco a permanência.

Outro elemento importante para nossa análise está no fato de que a Artes continuou como componente curricular na LDB, não houve desmembramento das partes que a compunham e a música continuou sendo uma de suas linguagens a ser trabalhada na própria disciplina, que já faz parte dos currículos escolares.

O componente curricular Artes, previsto na LDB abrange quatro linguagens artísticas a saber: Dança, Teatro, Artes Visuais e Música. E ao ser analisado via formação, já é percebida uma discrepância. Desde a LDB de 1996 que a formação não acontece mais em Educação Artística, o que na teoria abordava as quatro linguagens durante a formação, a partir de então a formação é específica em uma das linguagens.

Esses momentos descritos, desde a entrada do projeto de lei até o veto, constituem-se no que chamamos, de acordo com Mainardes (2006), de produção dos textos. Neste contexto são apresentadas as propostas e soluções, tornando-se descritas as ações que serão abrangidas pelas políticas públicas, neste caso, política pública educacional.

A partir de agora entra em ação a implementação, ou seja, restando colocar os textos produzidos no campo político em prática. É nesse momento que as interpretações e discrições dos burocratas são colocadas em ação. Nesse caso específico estamos entendendo como burocratas os membros do Ministério da Educação, das secretarias estaduais e municipais de educação, entre 
e-ISSN: 2525-3514

outros atores capazes de interpretar e colocar a lei em funcionamento ou não, de acordo com seu entendimento e de suas condições.

O primeiro aspecto a ser considerado é o que preconiza a lei, trazendo a música como conteúdo obrigatório, mas não exclusivo do componente curricular Artes. Ao ler essa afirmativa, é possível pensar que se a música já é parte de Artes, não será preciso mudar nada, porque ela já está contemplada. A música é um conteúdo obrigatório, portanto será preciso contemplá-lo em qualquer disciplina ou será preciso inserir uma disciplina nova na educação básica? Projetos extracurriculares na escola contendo música atendem a demanda criada pela Lei? Essas e várias perguntas podem surgir devido ao fato da decisão e da produção dos textos não terem sido tão claras e objetivas quanto deveriam ser, gerando dúvidas com relação à implementação, além de ampliar cada vez mais a discrição dos burocratas.

Outro ponto diz respeito ao profissional para lecionar diante do veto. De acordo com a LDB o profissional capacitado para lecionar na educação básica tem de possuir formação em nível superior em cursos de licenciatura ou possuir formação em nível médio na modalidade normal para atuar na educação infantil. Este veto presidencial está em desencontro com a própria LDB.

Sem a clareza se seria ou não disciplina, se estaria contemplada por outras formas de trabalho com a música na escola, de quais profissionais estariam habilitados para lecionar, e se de fato deveria ser lecionada, muitos estados e municípios não realizaram a inserção da música na educação básica. Muitos municípios implementaram a música como disciplina no ensino fundamental I, porque se consegue mais maleabilidade na estrutura do currículo. Já alguns estados e municípios aproveitaram do tempo integral como projeto para colocar a música de forma não permanente, vinculado a duração do projeto. As "mudanças" proporcionadas pela lei podem se enquadrar na concepção de Rua (1998) dentro do Modelo Incremental, ou seja, sem realizar grandes mudanças na estrutura.

Isso mostrou o lugar que a música deveria, ou melhor, não deveria ocupar na educação básica, um lugar no entremeio da lei e da realidade das escolas, ampliando as indefinições, deixando a cargo das interpretações dos implementadores se a música entraria ou não no currículo.

Com tantas indefinições, no ano de 2016 a obrigatoriedade do conteúdo música foi excluída pela Lei $\mathrm{n}^{\circ}$ 13.278, que alterou o parágrafo $6^{\circ}$ da LDB 9.394/96, voltando assim com a música como linguagem a ser contemplada apenas dentro da disciplina Artes, juntamente com o Teatro, a Dança e as Artes Visuais. 


\section{Conclusão}

Ficou evidente que a educação é um dos direitos centrais do campo social e como vimos a inserção ou não da música na escola foi tratada com dubiedade, deixando a cargo dos burocratas conduzirem os processos, dos quais a discrição imperou mais que a lei.

É preciso lembrar que a educação musical não era o propósito inicial, mas sim a criação do Plano Nacional de Cultura, que por diversos motivos acabou contribuindo para que os educadores musicais se organizassem e fosse fortalecida a demanda de música na escola. Isso já demonstrava que não era objetivo tratar da educação musical, mas ela surgiu como resultante de um processo de discussão e um meio de organização cultural, gerando campo propício para somar forças dos educadores em prol da causa.

Outro aspecto importante é que a aprovação da lei que insere a música como conteúdo não era suficiente para que ela se tornasse de fato disciplina. Os legisladores não apontaram para novas políticas que dessem sustentabilidade e possibilidades de entrada e permanência da música no contexto escolar. Aprovar a lei da música na escola era apenas o primeiro passo, pois era preciso formar mais profissionais, adequar os sistemas de ensino para contemplar mais um saber na escola e instruir os estados e municípios sobre como deveria ser o processo de adequação quanto a nova estrutura. Assim, a chegada da música na escola não deveria ser configurada como problema.

Do mesmo modo como a lei da música na escola não foi efetiva, várias outras legislações, em várias áreas, não só no campo da educação, também passam pelos mesmos percalços, ficando a cargo dos burocratas personalizá-las, materializá-las. E por representar de forma física o Estado, indo na mesma direção ou em direção contrária às normativas a que são submetidos, gerando desdobramentos talvez nunca pensados pelos formuladores da produção legislativa. 


\section{Referências}

BRASIL. Constituição da República Federativa do Brasil. Brasília, DF: Senado Federal: Centro Gráfico, 1988. 292 p.

BRASIL. Lei no 9.394, de 20 de dezembro de 1996. LDB: Lei das Diretrizes e Bases da Educação nacional. Estabelece as diretrizes e bases da educação nacional. Brasília, DF. 1996.

BRASIL. Lei n ${ }^{\circ} 11.769$, de 18 de agosto de 2008. Dispõe sobre a obrigatoriedade do ensino de música na educação básica. Brasília, DF. 2008

BRASIL. Lei no 13.278, de 2 de maio de 2016. Fixa as diretrizes e bases da educação nacional, referente ao ensino da arte.

CARVALHO, Ailton Mota de. Políticas sociais: afinal do que se trata? Agenda Social. Revista do PPGPS / UENF. Campos dos Goytacazes, v.1, n.3, set-dez/2007, p. 73-86,

CARVALHO, José M. Cidadania no Brasil: o longo caminho. Rio de Janeiro: Civilização Brasileira, 2004.

MAINARDES, J. Abordagem do ciclo de políticas públicas: uma contribuição para a análise de políticas educacionais. Educ. Soc., Campinas, vol. 27, n. 94, p. 47-69, jan./abr. 2006.

MEYERS, Márcia.; VORSANGER, Susan. Burocratas de nível de rua e a implementação de políticas públicas. In: PETERS, G \& PIERRE, J. Administração Pública Contemporânea. São Paulo: Editora UNESP, 2013.

PEREIRA, Luis F.R. Um movimento na História da Educação Musical no Brasil: uma análise da campanha pela Lei 11.769/2008. 2010. 2010. 450 f. Dissertação (Mestrado em Música) Programa de Pós-Graduação em Música, Centro de Letras e Artes, Universidade Federal do Estado do Rio de Janeiro, 2010.

QUEIROZ, Luis Ricardo Silva. Música na Escola: aspectos históricos da legislação nacional e perspectivas atuais a partir da Lei 11.769/2008. Revista da ABEM, v.20, n. 29; p. 23-38, jul-dez 2013.

RUA, Maria das Graças. Análise de Políticas Públicas: Conceitos Básicos. In: RUA, Maria das Graças; VALADAO, Maria Izabel. O Estudo da Política: Temas Selecionados. Brasília: Paralelo $15,1998$.

SOBREIRA, Sílvia. Reflexões sobre a obrigatoriedade da música nas escolas públicas. Revista da ABEM, Porto Alegre, v. 20, 45-52, set. 2008. 
SOUZA, Celina. Políticas Públicas: uma revisão da literatura. Sociologias, Porto Alegre, ano 8, n. 16, p. 20-45, jul/dez. 2006.

Recebido em 13 out. 2019 / Aprovado em 18 nov. 2019

\section{Para referenciar este texto}

MATIAS, Breno Henrique; JARDILINO, José Rubens Lima. Políticas públicas e seus ciclos na área educacional: o caso do ensino de música. Cadernos de Pós-graduacão, São Paulo, v. 18, n. 2, p. 49-62, jul./dez. 2019. Disponível em: < https://doi.org/10.5585/cpg.v18n2.15862>. 